\title{
ARTE NA ESCOLA: A CONSTRUÇÃO DA HISTÓRIA DA ARTE A PARTIR DO LEITOR
}

Maria Luiza Calim de Carvalho Costa ${ }^{1}$

Guiomar Josefina Biondo ${ }^{2}$

\section{Resumo}

Entendemos a imagem como um texto, ou seja uma trama, uma rede, que emana sentido, pensamos, então, no espectador de uma obra imagética como um leitor. Descartamos a linha do tempo como caminho de aproximação do leitor à obra, buscamos trajetos constelativos ou rizomáticos, propomos que cada leitor trace seu caminho de leitura e com isso tenha uma participação ativa na construção do sentido.O trabalho do professor envolve sensibilidade e conhecimento: em um primeiro momento como instigador para gerar o interesse ou a necessidade, e num segundo momento como alimentador do repertório, oferecendo outros textos verbais ou não-verbais para que o aluno trace seu caminho de leitura.

Palavras-chave: História da Arte; Leitura; Arte na Escola.

\begin{abstract}
We think a image as a text, a woof, a web, that emanates meaning, so we think, also, the espectator of a master-piece as a reader. We got rid of the history periods line as a way of approach the reader at the master-piece, we seek constelatives or rizomatics ways, we purpose that which reader sketches his reading way and so has a co-ative participation in meaning production. The teacher`s work involves sensibility and knowledge: in a firth moment as incite propositor to wake up the atemption and in other moment as a repertory feeder, showing others texts, verbals or not, for the student sketches his ways of reading.
\end{abstract}

Keywords: Art History; Reading; Art in School.

\section{Qualificar processos educacionais em arte}

O espaço da sala de aula, na maioria das vezes, igual e rotineiro, precisa ser tocado pelo espírito indagador e transformador da arte. Esse espaço contém a energia vibrante da vida, como espaço de troca, aprendizado e transcendência. Os conteúdos de arte instigam os alunos a expedições através dos tempos, a incursões no interior do ser, a redescoberta da vida sob um novo olhar. A arte possibilita esse olhar que indaga e não se conforma com o que é dado, quer ver por outro ângulo, sob uma nova perspectiva, esse olhar abdutivo, que lança hipóteses, que propõe novas possibilidades.

Em nosso Projeto de Extensão, Pólo Bauru FAAC/UNESP Arte na Escola, trabalhamos para que o espaço da sala de aula seja tocado por esse olhar abdutivo, gerador de possibilidades e propiciador de construir o conhecimento a partir da noção de polifonia, intertextualidade e multissemia inerentes aos textos estéticos. Descartamos a linha do tempo como caminho de aproximação do leitor à obra, buscamos trajetos constelativos ou rizomáticos, propomos que cada leitor trace seu caminho de leitura e com isso tenha uma participação ativa na construção do sentido.

O Pólo é uma parceria entre UNESP e Instituto Arte na Escola que nasceu do compromisso entre as instituições de contribuir para o ensinar e aprender arte na esfera da

${ }^{1}$ FAAC- UNESP/Bauru
${ }^{2}$ FAAC- UNESP/Bauru. 
Educação Básica (Infantil, Fundamental e Médio) e da Educação Superior, na sua atividade de extensão. As Instituições partilham a missão de qualificar processos educacionais em arte. Ser agente qualificado de transformação e fonte de referência no ensino da arte através de ações como: Educação Continuada que subsidia e apóia a as atividades do professor de arte; Dvdeteca que proporciona acesso a recurso da imagem móvel como instrumento de ensino e elementos motivadores para o aluno. Materiais de Apoio para o professor que possibilitam a difusão de novas propostas de interação do aluno com a obra de arte.

\section{Leitura: interação entre o leitor e o texto}

Se entendermos a imagem como um texto, ou seja uma trama, uma rede, que emana sentido, cujo código, ao invés de palavras, utiliza-se dos elementos visuais como estruturas significantes, então, podemos pensar no espectador de uma obra imagética como um leitor. Portanto, a apreciação de uma obra seria uma questão de leitura.

A leitura apresenta uma dupla condição: é um ato privado da consciência, ao mesmo tempo em que é uma atividade inscrita num tempo e lugar históricos, portanto social. Roger Chartier ${ }^{3}$ expõe que a leitura é sempre apropriação, invenção, produção de significados. A liberdade leitora, de que fala Chartier, não é absoluta, é cerceada por limitações derivadas das capacidades, convenções e hábitos que caracterizam, em suas diferenças as práticas de leitura. Então, "os gestos mudam segundo os tempos e lugares, os objetos lidos e as razões de ler". Segundo ainda Chartier, cada leitor, para cada leitura, em cada circunstância, é singular. "Mas essa singularidade é ela própria atravessada por aquilo que faz que este leitor seja semelhante a todos aqueles que pertencem à mesma comunidade" (CHARTIER,1998, p.77, 91-92).

Se os gestos mudam segundo tempos e lugares, é claro, que, por mais que o leitor recomponha o tempo de produção do texto a ser lido, usará, em sua leitura, as lentes do presente e do local onde pisa. Desse modo, no ato de leitura, há uma permuta de valores, pois o leitor traz o texto para seu mundo, como também leva sua visão de mundo para interferir no texto.

Jauss $^{4}$ destaca que reconstituir o horizonte de expectativa do leitor, ou seja a leitura dominante da época da produção da obra, orienta o leitor no atual processo de leitura, e possibilita a visualização da dimensão da novidade e impacto da obra no momento da publicação. Para Jauss, o horizonte de expectativa é coordenado por normas essencialmente estéticas como: o conhecimento, por parte do leitor, a respeito do gênero a que pertence a obra, o repertório herdado de leituras anteriores e a distinção vigente entre linguagem poética e linguagem prática.

\section{A leitura da obra de arte: um trajeto a ser percorrido}

Jauss propõe uma primeira leitura que consiste na atividade da percepção estética; uma segunda leitura que constitui uma exegese retrospectiva e uma terceira leitura, a histórica que reconstitui o horizonte de expectativa no qual se inscreveu o texto no contexto de sua produção. A tríade compreensão/interpretação/aplicação tem sido o problema metodológico da hermenêutica. A compreensão é a ação do leitor, no ato de uma primeira leitura reconhecer o código em que se expressa a obra, percorrer a narratividade e seu desdobramento. A interpretação está ligada à primeira leitura; é, porém, uma leitura mais

\footnotetext{
${ }^{3}$ CHARTIER, Roger. Aventura do Livro- do leitor ao navegador. São Paulo: Editora UNESP, 1998.

4 JAUSS, Hans Robert. Limites e Tarefas de uma Hermenêutica Literária. In Poetik und Hermeneutik vol. IX. Monique, 1980.
} 
atenta à estrutura da obra, ou seja, como o texto foi construído para auxiliar, orientar e reconduzir a compreensão. A aplicação inclui os dois momentos anteriores, transporta o texto do passado para dentro do presente (atualização), para assim emitir um julgamento estético.

Entretanto, para atualizar os diferentes níveis do texto, o leitor precisa se municiar de uma competência que o habilite ao processo de leitura. O leitor deve ter uma competência lingüística, ou seja conhecer o código, uma competência para perceber e selecionar as unidades relevantes do contexto e das circunstâncias, uma capacidade de interpretar o "hipercódigo retórico e estilístico" (Eco), um repertório para poder identificar as intertextualidades e uma competência de reconhecimento de visão ideológica do texto.

O leitor desconstrói o texto, para, a partir da relação entre cada elemento, constituir a sua interpretação. Não se trata de encontrar um centro, como a postular a existência de uma significação original e central, de relacionar a obra com uma intenção, uma origem que garanta a unidade de sentido, ou seja transformar o que é diverso em único. Trata-se, sim, de uma "leitura disseminadora e centrífuga", cuja origem é o desconstrutivismo derridiano. "Já que todo signo se constitui a partir das diferenças que o opõem aos outros; a linguagem não tem, portanto, nem centro, nem início, não existe local original. Assim, é impossível conceber ler um livro como um todo: os sentidos de um texto - inútil querer fixá-los - se fazem e se desfazem sem parar" (JOUVE,2002,p.98).

A ambigüidade da linguagem poética dá ao leitor um papel ativo na recepção: transforma-o em co-criador, produtor de sentido. O leitor adentra o jogo da leitura "com os sentidos despertos para apreender o inesperado, mais insinuado do que dito, porém capaz de reformular sua visão do Universo" (FERRARA, 1986,p.19).

Há, para o leitor/espectador um aprendizado a ser desenvolvido: aprender a olhar.

Alfredo Bosi ${ }^{5}$ distingue olho de olhar, levantando na etimologia de palavras em várias línguas como oeil e regarder em francês, ojo e mirada em espanhol, eye look em inglês, a percepção, no corpo dos idiomas, de que o olho é órgão receptor externo e olhar é o "movimento interno do ser que se põe em busca de informações e de significações".

A percepção dentro da corporiedade, como propõe Merleau-Ponty, é o olhar fenomenológico que "envolve, apalpa, esposa as coisas visíveis", é o olhar que o leitor contemporâneo precisa desenvolver para ter trânsito neste mundo contraditório, múltiplo, simultâneo, com imbricações, entrelaçamentos e correspondências. Para Merleau-Ponty, não podemos separar corpo-alma, razão-percepção, pois o olhar está enraizado na corporiedade. A percepção do mundo se dá como um todo, através da leitura de todos os sentidos e do intelecto simultaneamente. Não pode ser seccionado em só intelecto ou só percepção sensorial. Nos dizeres de Merleau-Ponty, "todo saber se instala nos horizontes abertos da percepção" (NOVAIS,1995,p.14-15).

O leitor deve, então, unir percepção e intelecto, despir-se do já concebido para ser capaz de desvelar o que nunca fora visto. A experiência estética é simultaneamente prazer e conhecimento e pode ser transgressora, quando há rompimento com o pré-estabelecido.

A arte revela conhecimentos construídos pela humanidade nas diversas áreas e evidencia a visão de mundo própria de cada época e própria de cada artista. Arte é fruição estética e documento histórico. A obra de arte está entre o particular e o universal da experiência humana.

${ }^{5}$ BOSI, Alfredo. Fenomenologia do Olhar. In NOVAIS, A. (org) O Olhar. São Paulo: Companhia das Letras, 1995. 
O processo de conhecimento, na comunicação artística, advém das relações significativas que o leitor/espectador realiza no ato de fruição e apreensão da obra. É a partir da percepção das linhas, texturas, cores, etc; e das relações significativas que o leitor traça, por meio da sensibilidade, imaginação, intelecto, que o significado se constrói.

O objeto se situa em rede na qual o leitor constrói o significado de acordo com o tipo de comunicação, freqüência e associação simbólica que faz. O leitor elege as conexões de acordo com o juízo perceptivo e desenvolve a capacidade de ampliar a rede, quanto mais exercita a leitura e as possibilidades associativas.

\section{A construção do jogo estético}

A produção da obra é construção, produto do olhar interpretativo do artista sobre o objeto a que se depara. É construção estética onde o estilo de época - o modo de construir o objeto artístico de um tempo - influencia a produção individual do artista.

A construção da obra de arte, em sua materialidade - os elementos visuais e o modo como estão organizados no campo plástico - oferece o caminho, ao leitor, para uma abordagem formal. Diante de uma obra de arte, o leitor/espectador pode em um primeiro momento depreender um olhar que perscruta a forma, esquadrinha o espaço plástico para investigar os materiais, a organização espacial e as técnicas empregadas. Esse olhar descritivo observa todos os elementos formais que compõem a obra. O leitor, através da leitura formal, entra em contato com o olhar do artista, através da especificidade da linguagem artística.

O professor pode criar situações em que o aluno é instigado a observar os elementos formais de uma obra estética e, talvez, reproduzi-los, com o intuito de aguçar a percepção dos detalhes e da especificidade do uso da linguagem artística. Essa reprodução só se justifica se tem por objetivo esse momento de apreensão e observação dos elementos formais da obra ou como possibilidade de entendimento da especificidade da linguagem artística. Não se trata de releitura, mas de uma leitura lúdica, com um fazer que busca percorrer o fazer do artista, na tentativa de realizar o mesmo caminho para encontrar um trajeto de leitura.

\section{O sentido emana da trama do jogo estético}

Da construção emerge o sentido. Ao perscrutar a obra de arte, o leitor-espectador vê emergir por entre a trama bem elaborada da produção estética o aspecto cognoscitivo da arte. $\mathrm{Na}$ estrutura do texto plástico estão os indicativos de leitura. Ao leitor impõe-se a tarefa de encontrar as pistas que levam às relações intertextuais e intratextuais a fim de instaurar o sentido da obra. O sentido não é único, a obra estética é multissêmica, polifônica, aberta; o ato de leitura requer do leitor mais do que um esforço de decifração: o leitor precisa reconstruir as relações, desvelar suas possibilidades.

Nesse momento, o professor pode oferecer ao aluno informações sobre o período da produção da obra, sobre o artista, sobre o movimento artístico em que se insere a obra. Tomando o cuidado para não dirigir a leitura, nem para fazer com que o contexto se torne mais importante que o próprio texto - a obra de arte. Oferecer elementos para que os alunos encontrem as pistas, os pontos de ancoragens, indicados na própria construção da obra: na linha, na cor, na forma, no volume, na textura, etc, sem contudo, dar o caminho. A obra deve ser o estímulo para que o aluno busque o sentido. O conhecimento que advém da obra deve ser escavado, restaurado, relacionado, atualizado pelo leitor. 


\section{O efeito estético revelado}

Ao entrar em contato com a obra de arte, o leitor exercita sua sensibilidade. O efeito estético fornece ao leitor sensações que não se pode aferir, estão no universo do sensível e envolvem o leitor em um enredamento de reações sensoriais. É o momento da fruição, momento individual entre obra e receptor, que inicia e, de certo modo, completa o trajeto de leitura. É esse efeito estético que joga o leitor à busca pelo sentido assim como é ele, através da dimensão fenomenológica, que faz com que o leitor considere suas sensações como elementos implicadores no sentido do texto estético.

A obra expressa o olhar do artista, a sua visão. $O$ leitor ao fruir a obra realiza com a totalidade de seus sentidos o efeito estético da obra. A expressão do artista entra em contato com a capacidade de sentir do leitor. Nesse momento, de certo modo, através da obra de arte, há um encontro entre o ser sensível do artista com o do leitor.

Nesse momento, o da fruição, que ocorre na primeira vez em que o leitor vê a obra e reaparece, quando o leitor instaura o significado unindo o formal, o cognoscitivo e o sensível, o professor deve deixar fluir sem sua interferência.

O professor pode orientar sua aula, a partir daí, oferecendo estímulos para que o aluno relacione o sentido da obra recém fruída, compreendida e interpretada para uma aplicação. Uma atualização, pode ser sugerida. Novamente, insisto, não é uma releitura, enquanto cópia. Uma atualização poderia ser uma análise crítica de como o sentido da obra pode se ligar com questões contemporâneas, por exemplo. Também poderia ser sugerido que o aluno fizesse uma transposição de linguagem artística, considerando, evidentemente o sentido instaurado da obra. Então, uma pintura poderia ser transposta para uma linguagem cênica, ou para uma linguagem musical, e assim por diante.

\section{O tempo da produção e o da recepção: o recorte sincrônico do tempo histórico}

O olhar do artista possibilita, ao leitor-espectador de sua obra, uma nova perspectiva de olhar. O encontro desses olhares - do artista e do leitor-espectador- sobre um mesmo objeto, ou tema, já se transforma em um diálogo que atravessa o tempo. Diante de uma obra, o leitor-espectador encontra-se com o seu produtor e sua visão de mundo, encontra-se também, com o tempo da produção da obra e com o universo sócio-político-cultural desse tempo-local, o que faz da leitura de uma obra de arte uma viagem ao mesmo tempo interior - quando em contato com o modo de ver do artista, e, uma viagem geo-histórica - quando em contato com o tempo-lugar de produção da obra. Nessa viagem, o leitor não se desvencilha do olhar de seu tempo, o que faz gerar um diálogo entre dois tempos: o da produção da obra e o do leitor. O tempo que me refiro aqui, é o tempo/espaço sóciopolítico-cultural em que se situa a produção e a recepção.

$\mathrm{O}$ ato de leitura de uma obra de arte, leva então a um processo de busca de significados, implícitos ou explícitos, marcados pelo tempo e espaço em que foram produzidos, assim como, é claro, pelo o olhar do artista e sua visão de mundo. Esses significados entram em diálogo com o tempo e espaço em que se encontra o leitor e sua visão de mundo contemporânea. Esses diálogos, de acordo com o repertório do leitor, vão se constituir em redes com conexões, num encadeamento de relações que só se esgotam quando o leitor se der por satisfeito com o significado. Ou seja, quanto mais relações intertextuais o leitor for capaz de fazer, mais complexa a trama da rede, que tende ao infinito em suas relações.

Então, o leitor traça trajetos de leitura, que dependerá de seu interesse ou necessidade, dependerá, também, de seu repertório e de sua capacidade de relacionar outros textos já vistos ou lidos. 
Aí entra o trabalho do professor, em um primeiro momento como instigador para gerar o interesse ou a necessidade, e num segundo momento como alimentador do repertório, oferecendo outros textos verbais ou não-verbais para que o aluno trace seu caminho de leitura. Atenção, o aluno traça seu caminho de leitura, que não é o do professor. $\mathrm{O}$ aluno deve ser incentivado a procurar outras relações intertextuais, não se limitar ao que o professor lhe oferece. De acordo com a faixa etária dos alunos, o professor deve, então, estimular esse passo lançando um problema para que os alunos resolvam, a partir de uma pesquisa. Essa pesquisa poderá relacionar a obra com o presente local, regional ou global em que se situa o aluno. Ou seja, o professor abre a possibilidade de um diálogo mais profundo entre a obra, o aluno-leitor e o contexto em que ele, aluno, está inserido.

A arte para ser arte deve travar um diálogo com o seu tempo. Para ser arte, atravessa o tempo, e adquire um caráter atemporal, podendo promover diálogos com outros presentes. As múltiplas possibilidades que o leitor tem de criar trajetos de leitura salientam a ambigüidade existente em uma obra artística.

Assim, a arte se apresenta como feixe de possibilidades, como transgressão da mesmice, da opacidade cotidiana. Em uma sala de aula: quatro paredes, janelas, carteiras, porta, lousa, armário; a possibilidade de uma viagem no centro do humano, ao redor do mundo, no centro da comunidade em que se vive, no interior de nós mesmos.

\section{Bibliografia}

BOSI, Alfredo. Reflexões sobre a Arte. São Paulo: Editora Ática. 2002.

. Fenomenologia do Olhar. In NOVAIS, A. (org) O Olhar. São Paulo: Companhia das

Letras, 1995.

CHARTIER, Roger. A Aventura do Livro: do leitor ao navegador - Conversações com Jean Lebrun. São Paulo: Editora UNESP,1998.

FERRARA, Lucrécia D`Aléssio. A Estratégia dos Signos. São Paulo: Perspectiva,1986.

. Leitura sem Palavras.São Paulo: Editora Ática,2000.

ISER,Wolfgang. A interação do texto com o leitor. In: LIMA, Luiz Costa (org). A Literatura e o Leitor. Rio de Janeiro: Paz e Terra,1979.p 83 - 132.

O Ato de Leitura. São Paulo: 34, 1996.

JAUSS, Hans Robert. A História da Literatura como Provocação à Teoria Literária. São Paulo: Ática, 1994.

JAUSS, Hans Robert. Limites e Tarefas de uma Hermenêutica Literária. In Poetik und Hermenentik vol.IX. Monique, 1980.

JOLY, Martine. Introdução à Análise da Imagem. Campinas: Papirus Editora,1999.

JOUVE, Vicent. A Leitura. São Paulo: Editora UNESP,2002.

MITCHELL, W. J. T. (org). The Language of Images. Chicago: The University of Chicago Press, 1980.

1986.

Iconology: Image, Text, Ideology. Chicago: The University of Chicago Press,

NOVAIS, Adauto. (org) O Olhar. São Paulo: Companhia das Letras, 1995.

PAREYSON, Luigi. Os Problemas da Estética. São Paulo: Martins Fontes,1997.

PLAZA, Júlio. Traducão Intersemiótica. São Paulo: Perspectiva, 1987. 